\title{
Carboxylic-plasma-treated nanofiller hybrids in carbon fiber reinforced epoxy composites: Dispersion and synergetic effects
}

\author{
D. Aussawasathien*, K. Hrimchum
}

Plastics Technology Research Team, Advanced Polymer Technology Research Group, National Metal and Materials Technology Center, 114 Thailand Science Park, Phahonyothin Road, Khlong Nueng, Khlong Luang, Pathum Thani 12120, Thailand

Received 22 June 2020; accepted in revised form 15 August 2020

\begin{abstract}
A nanostructuring approach was applied to epoxy/carbon fiber (CF) composite laminates to establish a short transport path between the $\mathrm{CF}$ of the adjacent laminates. This involved the utilization of carboxylic-plasma-functionalized multiwalled carbon nanotube (COOH-MWCNT) and carboxylic-plasma-functionalized graphene nanoplatelet (COOH-GNP) hybrids filled epoxy resin at various nanofiller hybrid ratios and concentrations. Novel Raman spectroscopy imaging and surface potential atomic force microscopy (AFM) mapping were employed to analyze the state of nanofiller dispersion on the laminate surfaces. The mixture of COOH-GNPs and COOH-MWCNTs in a ratio of 50:50 wt $\%$ at 4 phr was identified to synergetically improve their dispersion and the laminate electrical and mechanical properties. It offered optimal segregation of nanofiller hybrids. At this composition, the maximum electrical conductivity and the highest flexural strength were achieved in the composite laminate, which were approximately $75 \mathrm{~S} / \mathrm{cm}$ and $675 \mathrm{MPa}$, respectively.
\end{abstract}

Keywords: polymer composites, graphene nanoplatelet, multiwalled carbon nanotube, nanofiller hybrid, carboxylic-plasma treatment

\section{Introduction}

Carbon fiber reinforced polymer (CFRP) composites have been extensively employed in various high-performance applications such as aerospace, aircraft, automotive, civil engineering, and sporting goods due to their low density, high strength-to-weight ratio, excellent fatigue and corrosion resistance, and flexible design ability [1]. Epoxy resin is commonly selected as a polymer matrix in advanced CFRPs due to its high mechanical properties, great chemical resistance, ease of processing, and low cost [2]. Nevertheless, a major drawback of epoxy resin is its brittleness, which is unfavorable for interlaminar properties between the matrix and the reinforcement [3]. Therefore, the interlaminar interface nanostructuring has been explored to improve the through-thickness properties of CFRP composites by adding nanofillers to the polymer matrix [3-6]. Among various nanofillers, multiwalled carbon nanotubes (MWCNTs) and graphene nanoplatelets (GNPs) in CFRP composites have gained considerable attention for improving interlaminar mechanical, electrical, and thermal properties of the composite laminates [7, 8]. Both MWCNTs and GNPs have hexagonal structures of $\mathrm{sp}^{2}$ hybridized carbon atoms. However, MWCNTs have a one-dimensional (1-D) cylindrical shape with a high aspect ratio, and GNPs have a twodimensional (2-D) with multi-graphene layers. They both have large specific surface areas. These promote stress transfer from the polymer matrix to the

"Corresponding author, e-mail: daruneea@mtec.or.th (C) BME-PT 
nanofiller during applied forces [9-11]. The use of both nanocarbons are limited in some polymer composites since MWCNTs trend to entangle and agglomerate and GNPs aggregate and restack due to their large van der Waals forces and strong $\pi-\pi$ interactions between the planar nanosheets. These lead to poor interfacial interactions with polymers and low formation of networking structures for load, electrical, and thermal transfers in the composite materials [9-12].

Aside from dispersion procedures [13] and the addition of dispersing agents [14], a number of functionalization methods on nanofiller surfaces [15-18] were mainly investigated to create stronger interfacial interaction between nanofillers and organic polymers. The functional groups on the surface of nanofillers were usually chemically compatible with the host resin. However, the chemical functionalization caused some severe damages to the outer shell of MWCNTs, which obstructed the extension of $\pi$ conjugation and subsequently worsen their electrical conductivity $[19,20]$. Highly wrinkled sheets and defects on the graphene surface after oxidation and during thermal exfoliation were also found and resulted in low mechanical properties [21]. The current challenge associated with the chemical functionalization is the scalability since it is a tedious, dangerous, timeconsuming process, and environmental and human health hazard. Alternatively, plasma technology has been utilized to uniformly modify the top few nanometers of the material surface without destruction of its bulk compositions and properties. The process is favorably applied to enhance the interfacial affinity of composites [22-24]. This technology is an effective method, offering a variety of advantages such as shorter reaction time, an environmentally friendly process, and providing a broad range of functional groups based on the plasma parameters.

Various nanofiller hybrid combinations gained much attention, including GNPs with nanocarbon aerogels [4], few-layer graphenes with single-walled CNTs (SWCNTs), and nanodiamonds [25], CNTs with GNPs [26], and graphene oxide-CNT hybrids [27]. Moreover, the synergetic effect of the GNP/CNT hybrids used to reinforce epoxy/CF laminates was also investigated [28]. Even though the mechanism of the synergetic effect was not completely understood, the geometric shapes and the ratio of fillers in the mixture were found to be significant parameters, influencing nanofiller dispersion in the polymer matrix and final properties of the composites [4, 29, 30]. The presence of two nanofillers, CNTs and GNPs, in polymer composites, exhibited a co-supporting network. The platelet-like structure of GNPs shielded the tube-like geometry of CNTs from damages during applied loads and maintained good dispersion in the polymer matrix, thus, providing the property improvement [30]. Yue et al. [29] reported that the composite with the CNT:GNP mixing ratio of 8:2 exhibited the improvement of flexural properties and the reduction of the electrical percolation threshold. It resulted in a better CNT dispersion in the presence of GNPs, giving the formation of a conductive network. MWCNT/GNP hybrids with MWCNTs grown on the GNPs using the chemical vapor deposition (CVD) technique were employed to fabricate epoxy composites [31]. A synergetic effect between the MWCNTs and GNPs was observed with a uniform dispersion of MWCNT/GNP hybrids in the epoxy matrix. It demonstrated that these nanofiller hybrids were effective reinforcements for epoxy composites. Additionally, a simulation model was studied to explain the synergetic effect of CNTs and GNPs on the electrical and thermal conductivity of CNT/GNPfilled epoxy composites [32].

There have been many techniques such as optical microscopy (OM), transmission electron microscopy (TEM), AFM, and scanning electron microscopy (SEM), used to directly observe and qualitatively determine the nanofiller dispersion state at different scales. The UV-Visible spectroscopy was utilized to detect individual or small bundles of CNTs $[33,34]$ as well as to quantitatively evaluate CNT dispersion at the nano scale $[35,36]$. The rheological measurement of epoxy-CNT suspensions provided information on their microstructure and dispersion state [37, 38]. It was found that the CNT network became stronger by improving the CNT dispersion state. A higher storage modulus $\left(G^{0}\right)$ and complex viscosity $\left(\eta^{*}\right)$ were reported [37].

In previous studies, GNPs and CNTs without surface modification were mostly used in the nanofiller hybrid system for CFRP composites. To the best of our knowledge, there is no report on the use of $\mathrm{COOH}$ GNPs and $\mathrm{COOH}-\mathrm{MWCNTs}$ prepared by a plasma treatment process as nanofiller hybrids for enhancing the interfacial interaction between nanocarbons and the epoxy matrix and improving multifunctional properties of epoxy/CF composites in the throughthickness direction. Moreover, the characterization 
of nanofiller dispersion state on the composite surfaces, which is important information, relating to the final properties of CFRP composites, is also rarely investigated. Therefore, we proposed new methods to determine the dispersion of nanofillers on the surface of composite laminates using Raman imaging and AFM surface potential mapping techniques. More importantly, correlations between the state of nanofiller hybrid dispersion on the surface of composite laminates and the synergetic properties of $\mathrm{COOH}$-nanofiller hybrid filled epoxy/CF composite laminates, particularly in the through-thickness direction, e.g., electrical conductivity and flexural strength, were investigated as well. Effects of different $\mathrm{COOH}-\mathrm{GNP}: \mathrm{COOH}-\mathrm{MWCNT}$ ratios and $\mathrm{COOH}-$ nanocarbon hybrid concentrations on the state of nanofiller dispersion, were systematically studied. With the proper combination of nanofiller hybrids, the improvement of nanofiller dispersion and composite laminate properties was obtained in this work.

\section{Experimental procedure}

\subsection{Materials}

Epoxy resin (Modified bisphenol-A type, Epotec YD $535 \mathrm{LV}$ ) and curing agent (Modified polyamines, TH 7257) supplied by Aditya Birla Chemicals (Thailand) Ltd., Rayong, Thailand were utilized as the polymer matrix. The CF (Pyrofil ${ }^{\mathrm{TM}}$ ) was produced by Mitsubishi Rayon Co., Tokyo, Japan, containing a filament count of 3000 and a yield of $200 \mathrm{~g} / \mathrm{m}$. $\mathrm{COOH}-\mathrm{MWCNTs}$ (HDPlas MWCNT-COOH) and $\mathrm{COOH}-\mathrm{GNPs}$ (HDPlas GNP-COOH) were received from Haydale Technologies (Thailand) Co., Ltd., Pathum Thani, Thailand. The specification of $\mathrm{COOH}-$ MWCNTs is as follows: diameter of $\sim 20 \mathrm{~nm}$, length of $10-100 \mu \mathrm{m}$, and density of $0.04-0.06 \mathrm{~g} / \mathrm{cm}^{3}$. Properties of COOH-GNPs are as follows: the planar size of $0.3-5.0 \mu \mathrm{m}$, thickness $<50 \mathrm{~nm}$, and density of $2.15 \mathrm{~g} / \mathrm{cm}^{3}$.

\subsection{Fabrication}

The epoxy:hardener mixing ratio of 70:30 $\mathrm{wt} \%$ was used throughout the experiment. Initially, epoxy/CF composite laminates containing different $\mathrm{COOH}-$ GNP:COOH-MWCNT ratios (i.e., 0:0, 100:0, 30:70, 50:50, 70:30, and 0:100 $\mathrm{wt} \%$ ) were prepared using a constant $\mathrm{COOH}$-nanofiller concentration, and a fixed $\mathrm{COOH}-n a n o f i l l e r$ hybrid filled epoxy: $\mathrm{CF}$ mass ratio of $1 \mathrm{phr}$ and $1: 1$, respectively. The $\mathrm{COOH}-$ GNP:COOH-MWCNT ratio of 50:50 wt $\%$ and
COOH-nanofiller hybrid filled epoxy:CF weight ratio of 1:1 were kept constant for the preparation of composite laminates at various $\mathrm{COOH}$-nanofiller hybrid loadings of $0,1,4,7$, and $10 \mathrm{phr}$.

In the polymer-nanofiller mixing process, the fillers were primarily dispersed in the epoxy resin by ultrasonication in a water bath (DTH Digital control, Branson Ultrasonics, Danbury, CT, USA) at room temperature for $1 \mathrm{~h}$ and then subsequently stirred using a high-speed mixer (RW 20 digital, IKA Works GmbH \& Co., Staufen, Germany) at $1000 \mathrm{rpm}$ at room temperature for $30 \mathrm{~min}$. After that, the curing agent was immediately added in the mixture before continuous mixing using a high-speed mixer at $1000 \mathrm{rpm}$ at room temperature for $5 \mathrm{~min}$. The $\mathrm{COOH}-$ nanocarbon/epoxy mixture was applied on a CF mat $(13 \mathrm{~cm} \times 13 \mathrm{~cm})$ using a hand-lay-up process. The nanocarbon filled epoxy-CF laminate was laid up one by one until the 15 layers of $\mathrm{CF}$ was obtained prior to compression molding using a hot plate (Lab-tech, Labtech Engineering Co., Ltd., Samut Prakan, Thailand) at $140^{\circ} \mathrm{C}$ under the pressure of 150 bar for $60 \mathrm{~min}$. The neat epoxy-CF composite laminate was also prepared and used as a reference sample for further comparison.

\subsection{Characterization}

The absolute viscosity of the epoxy resin with and without $\mathrm{COOH}$-nanocarbons was measured at room temperature using a digital rotary viscometer (NDJ9S, Jedto Instruments, Changping, People's Republic of China). The rotor type and rotor velocity were $3 \#$ and $60 \mathrm{rpm}$, respectively. The dispersion of $\mathrm{COOH}$-nanocarbons on the surface of composite laminates was analyzed using an atomic force microscope (AFM5500M, Hitachi, Tokyo, Japan) with Kelvin probe force mode (KFM) to create a surface potential map. The silicon cantilever coated with gold on both sides was dragged on the sample surface $(10 \mu \mathrm{m} \times 10 \mu \mathrm{m})$, except for the neat epoxy/CF composite laminate $(5 \mu \mathrm{m} \times 5 \mu \mathrm{m})$. In addition, the dispersion of $\mathrm{COOH}$-nanocarbons on the surface of composite laminates was also investigated using a high-resolution Raman spectrometer (L26Ram HR Evolution, Horiba Jobin Yvon, Villeneuve d'Ascq, France) equipped with microscope capabilities. The Raman 2D intensity mapping technique at the $\mathrm{G}$ band was used to make Raman mapping images. The $532 \mathrm{~nm}$ laser source was selected for characterization. The electrical conductivity of the composite 
laminates was determined by a four-point-probe measurement (Jandel Model 3, Jandel Engineering Ltd., Leighton Buzzard, United Kingdom), according to ASTM D4496. The surface resistivity was measured at twenty different locations on both sides of each specimen and then converted to the surface conductivity. The averaged value was reported as the electrical conductivity. The three-point bending test was conducted to measure the flexural strength of the composite laminates using a Universal Tensile Machine (INSTRON 5500R, Norwood, MA, USA), following ASTM D-790. The specimen dimension was $127 \mathrm{~mm}$ (length) $\times 14 \mathrm{~mm}$ (width) $\times 2.5 \mathrm{~mm}$ (thickness). The composite laminate was cut into specimens using a computer numerical control (CNC) method. The cross-sectional area of cut samples was examined using an optical microscope (Zeiss Axioskop, Micro Tech Lab, Graz, Austria) before the flexural test to ensure that the amount of porosity and voids was less than $5 \%$ of the total area. The punch speed was set at $4.1 \mathrm{~mm} / \mathrm{min}$, and the span length was $80 \mathrm{~mm}$. For each formulation, the flexural strength was averaged over five measurements.

\section{Results and discussion}

\subsection{Nanocarbon dispersion in epoxy resin}

The plasma functionalization on nanofiller surfaces was found to be an effective means to enhance the interaction between polymers and plasma-modified nanofillers owing to both physical (surface roughness) and chemical treatment (active polar groups) [22]. There was no observed separation between the modified nanocarbons and the epoxy resin for all formulations and periods $(0,1,2$, and $3 \mathrm{~h})$. It could be attributed to the $\mathrm{COOH}$-groups on nanofiller surfaces, resulting in strong interfacial interaction between COOH-nanofillers and the epoxy resin [23, 24].

The viscosity of epoxy/nanofiller suspension was an important factor that partly affected the dispersion of nanofillers on the surface and the interface of composite laminates [2]. Low suspension viscosity was anticipated to facilitate the uniform flowing of nanofiller filled epoxy resin to some degree during handlay-up and compression molding processes. The viscosity of epoxy/nanofiller suspensions was higher than that of the neat epoxy resin $(\sim 790 \mathrm{cP})$ and continuously increased from 850 to $1960 \mathrm{cP}$ with increasing COOH-MWCNT portions from 0 to $100 \mathrm{wt} \%$. In the previous work, it was reported that the plasma-treated nanofiller filled epoxy composites provided strong shear-thinning behavior and higher shear viscosity than the epoxy matrix [22]. On the basis of rheological analysis [37], as the state of nanofiller dispersion improved, the stronger nanofiller network occurred. This could be determined by a higher storage modulus and complex viscosity. The epoxy resin containing COOH-MWCNTs alone exhibited higher viscosity than that containing only $\mathrm{COOH}-\mathrm{GNPs}$ since $\mathrm{COOH}-$ MWCNTs had a lower density than COOH-GNPs. Therefore, a larger amount of COOH-MWCNTs was filled in the system at the same weight percent. The viscosity of epoxy/nanofiller suspensions went up approximately from 790 to $1970 \mathrm{cP}$ with increasing $\mathrm{COOH}$-nanofiller hybrid loading from 0 to $4 \mathrm{phr}$. Then, it reached a certain level of about $2000 \mathrm{cP}$ at 7 and $10 \mathrm{phr}$, which might be referred to as the initial state of the $\mathrm{COOH}$-nanofiller aggregation.

\subsection{Nanofiller dispersion on the surface of composite laminates}

\subsubsection{AFM mapping}

AFM mapping method based on the surface potential measurement was used for the first time to evaluate the distribution of nanofillers on the surface of the composite laminates. Principally, the existence of conductive fillers at a position on the composite laminate surface would exhibit a surface potential. On the AFM mapping image, the brightest area corresponded to the highest surface potential, while the darkest area indicated the lowest potential. The range of the potential was demonstrated in the color bar. The larger the varied surface potential, the poorer the nanofiller dispersion. Moreover, the distribution curve of surface potential values could be used to explain the nanofiller distribution. For instance, a narrow, smooth, and symmetry curve meant a better nanofiller distribution than the broad, spiky, and asymmetric curve. Figure 1 present AFM maps of the composite laminate surfaces on the basis of the surface potential mapping at a variety of $\mathrm{COOH}$ GNP:COOH-MWCNT ratios. The AFM mapping image of the unfilled epoxy resin/CF composite laminate as a reference sample showed lower surface potential $(\sim 220-240 \mathrm{mV})$ with less variation $(\sim 19 \mathrm{mV})$ than those of nanocarbon filled epoxy/CF composite laminates. Among the five prepared samples of each filled epoxy/CF composite laminate, the minimum surface potential difference of about $75 \mathrm{mV}(\sim 220$ $295 \mathrm{mV}$ ) was obtained for the 50:50 wt \% COOHGNP:COOH-MWCNT ratio. It was suggested that 


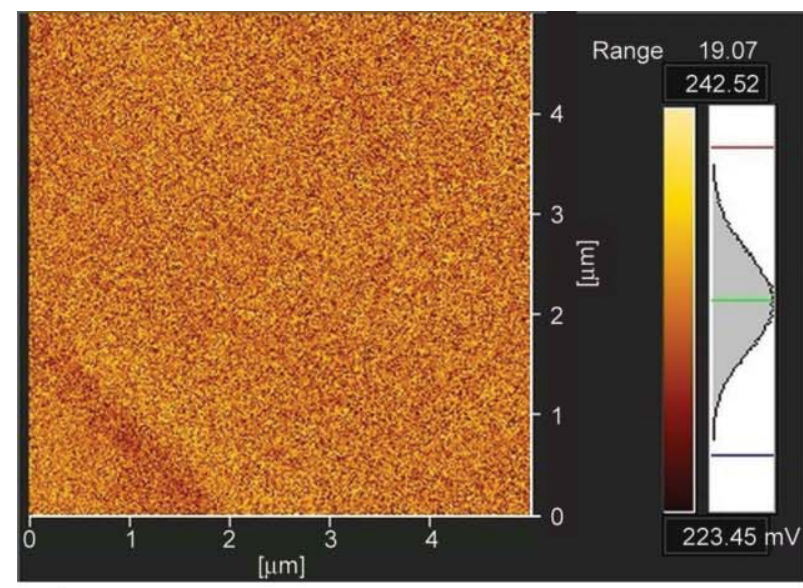

a)

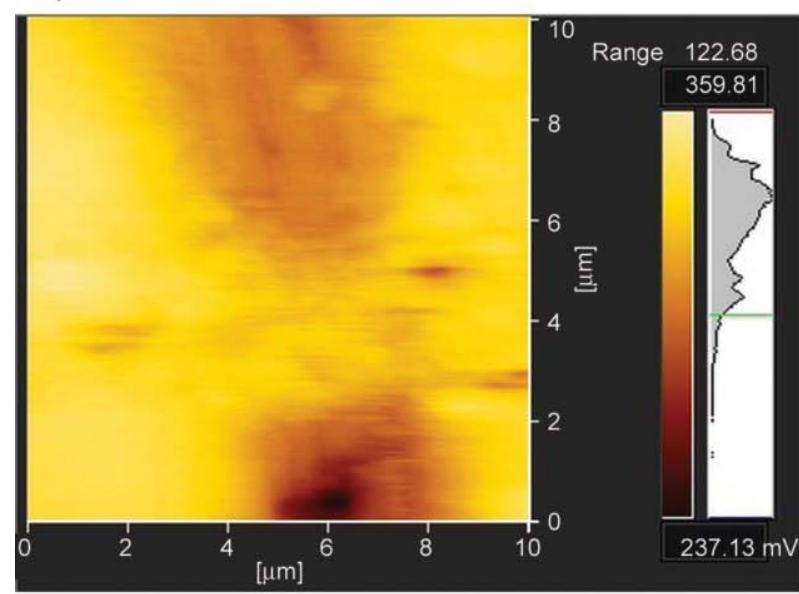

c)

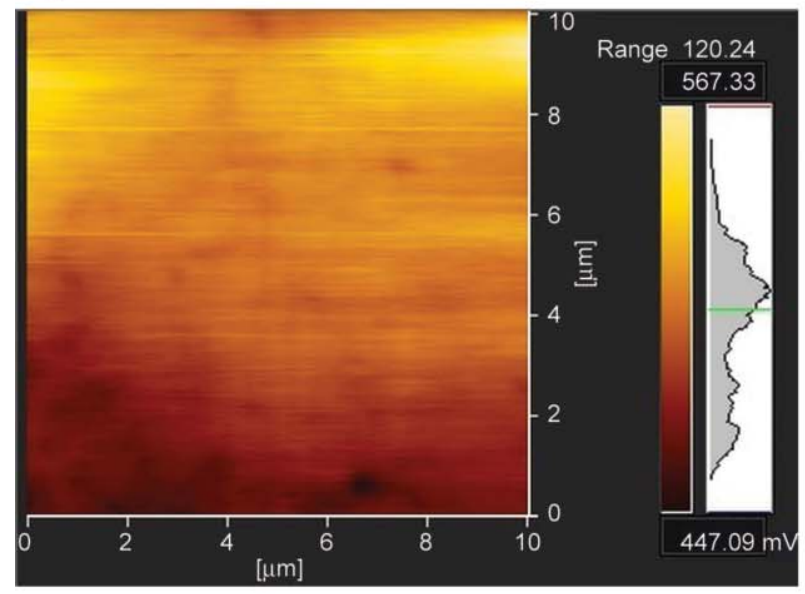

e)

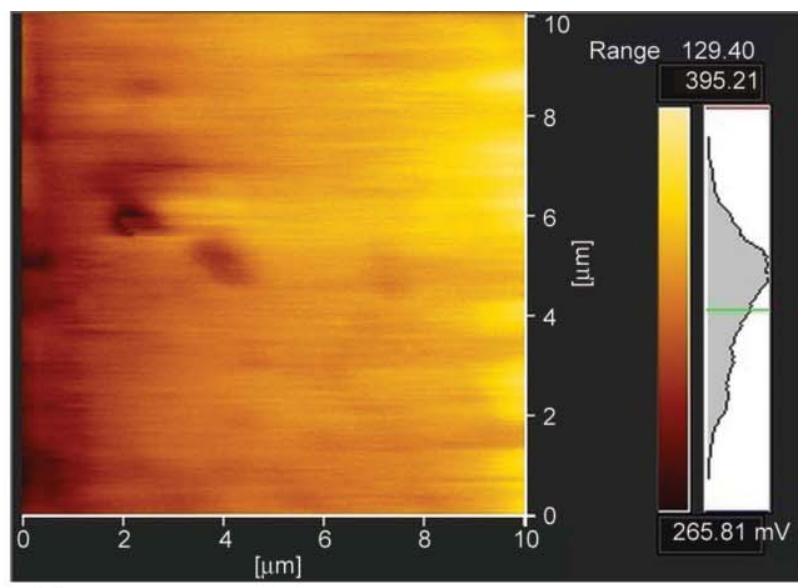

b)

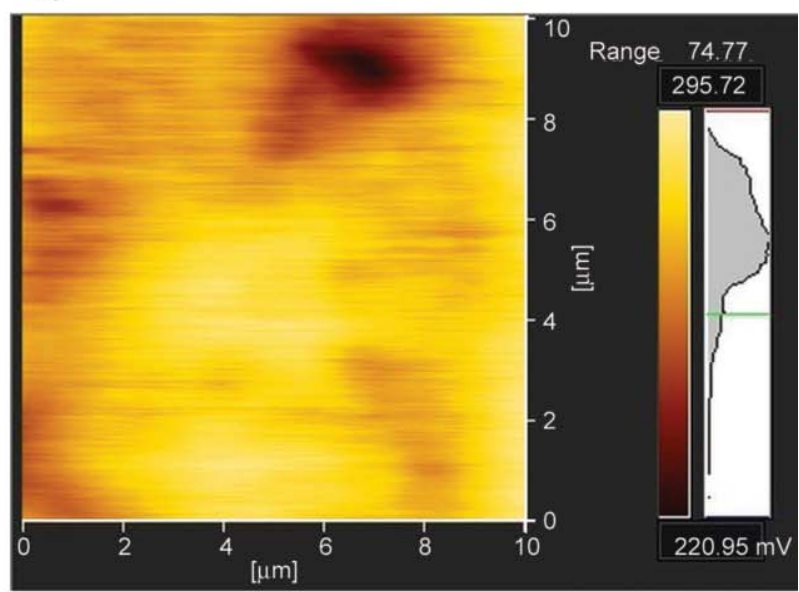

d)

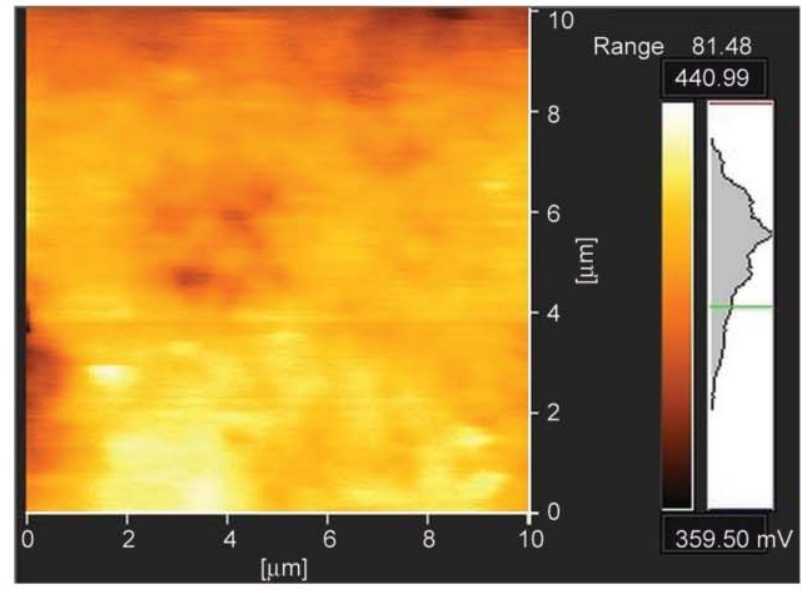

f)

Figure 1. AFM mapping images of the composite surfaces at various COOH-GNP:COOH-MWCNT ratios [wt $\%$ ] at $1 \mathrm{phr}$ : (a) 0:0 (unfilled epoxy resin), (b) 100:0 (all COOH-GNP), (c) 70:30, (d) 50:50, (e) 30:70, and (f) 0:100 (all COOHMWCNT).

the distribution of $\mathrm{COOH}-$ nanofillers on the composite surface at this ratio was the best. This indicated that both carbon nanomaterials were efficiently pervaded between each other, resulting in the formation of complementary structures that were beneficial to prevent restacking due to large van der Waals forces [26]. It was noted that the composite laminate containing $100 \mathrm{wt} \% \mathrm{COOH}-\mathrm{MWCNTs}$ possessed higher surface potential than that having only $\mathrm{COOH}-$ GNPs owing to higher COOH-MWCNT contents at the same weight percent, thus, more conducting networks were established. Therefore, the surface potential tended to decrease with increasing $\mathrm{COOH}-$ GNP portions. The distribution of COOH-GNPs 
seemed to be poorer than that of COOH-MWCNTs judging from the broader curve obtained from the composite laminate containing only $\mathrm{COOH}-\mathrm{GNPs}$. This might be due to larger van der Waals attraction and stronger $\pi-\pi$ interactions between the plane-toplane structure of adjacent nanoplatelets [4].

In order to enhance the nanofiller distribution and the intercalation between each modified nanofiller, the increment of filler dosages was suggested [4]. Figure 2 depict AFM maps derived from the surface potential characterization of the composite laminates at different nanofiller hybrid concentrations. The composite laminate containing $4 \mathrm{phr}$ nanofiller hybrids at 50:50 wt $\%$ COOH-GNP:COOH-MWCNT ratio showed the surface potential in the range of 300 $400 \mathrm{mV}$ together with the minimum surface potential difference of about $100 \mathrm{mV}$ and a good distribution curve of surface potential values. Even though the surface potential increased at higher nanofiller hybrid loadings, e.g., 7 and $10 \mathrm{phr}$, the broad and/or bimodal distribution curves with a large variation of surface potential values were also shown as a consequence of non-uniform segregation and partial agglomeration of nanofillers. These results are in agreement with the previous report that synergetic effects of combining GNPs with CNTs in the epoxy resin improved electrical conductivity. It was found that CNTs were intercalated between the GNP layers and vice versa, allowing the creation of conductive pathways within the polymeric matrix [39].

\subsubsection{Raman mapping}

The Raman spectroscopy is a well-known technique to examine the graphitic characteristics such as nanocrystalline, crystalline, and amorphous of CFs, GNPs, and MWCNTs [40]. Two principle peaks are mainly observed, including the graphitic band ( $\mathrm{G}$ band, $\sim 1500-1600 \mathrm{~cm}^{-1}$ ), indicating the tangent vibrations of $\mathrm{sp}^{2}$ crystalline graphitic and the disorder defect band (D band, $\sim 1350 \mathrm{~cm}^{-1}$ ) [41]. These two bands could be used to create Raman mapping images for investigating the nanofiller distribution on the surface of the composite laminates. The Raman mapping images derived from both $\mathrm{G}$ and $\mathrm{D}$ bands exhibited similar trends of the nanofiller distribution. This was a novel method and had not been reported in any literature. Figures 3 show AFM mapping images of the $\mathrm{G}$ band at different COOH-GNP:COOH-MWCNT ratios of 0:0 (unfilled epoxy resin), 100:0 (all COOHGNP), 50:50, and 0:100 (all COOH-MWCNT),

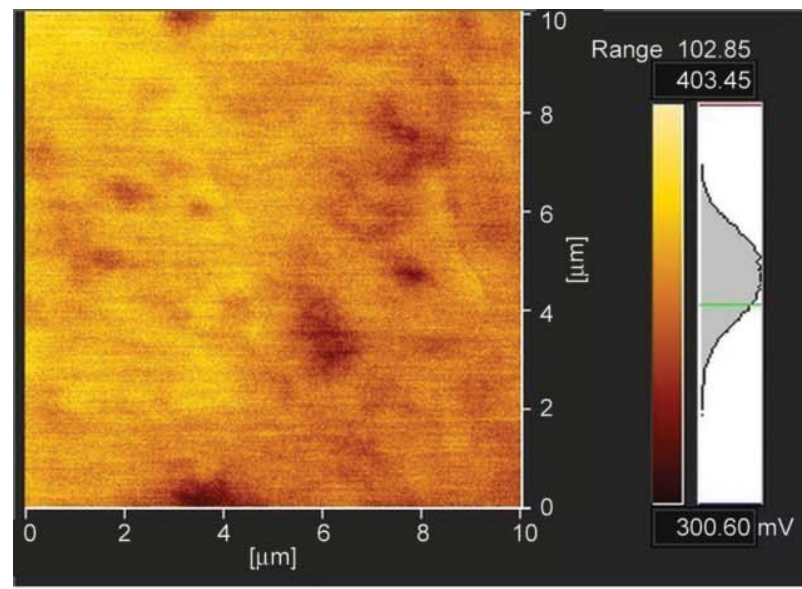

a)

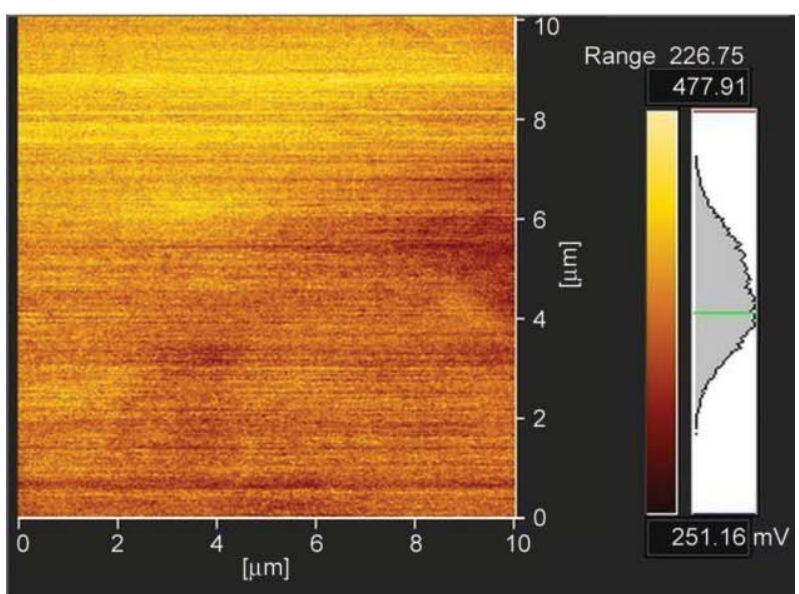

b)

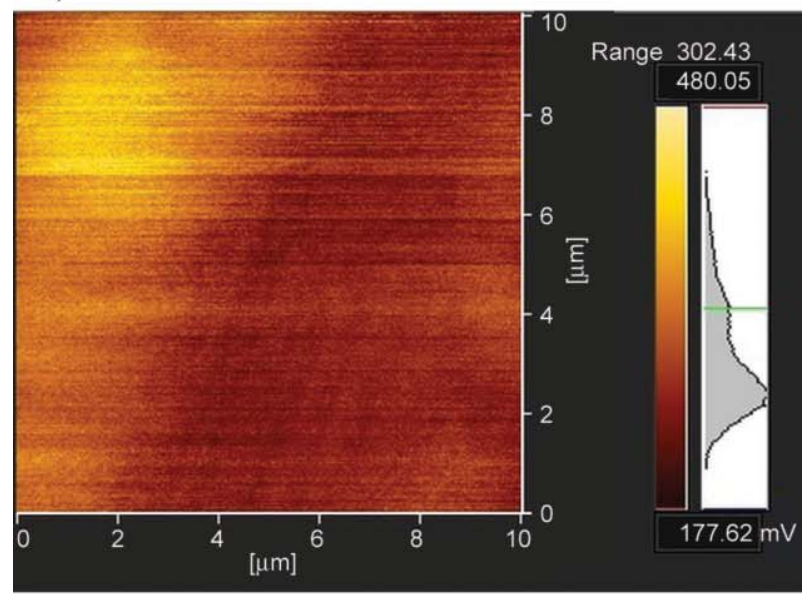

c)

Figure 2. AFM mapping images of the composite surfaces containing different $\mathrm{COOH}$-nanocarbon hybrid (50:50 wt $\%$ ) concentrations [phr]: (a) 4, (b) 7, and (c) 10 .

respectively. These ratios were selected to obtain Raman maps based on the previous AFM results (Figure 1). The dark blue areas indicated the absence of COOH-nanofillers, whereas the dark red areas corresponded to the highest amount of $\mathrm{COOH}$-nanofillers on the sample surface. The range of distribution was 
displayed by the color bar of the Raman maps. The variation of $\mathrm{COOH}$-nanofillers was identified by different shades on the mapping image. The Raman mapping image of the unfilled epoxy resin/CF composite laminate as a reference sample mostly showed the dark red areas due to the presence of CFs. Low amount of the dark blue areas partially presented on the image, which might be because of the non-uniformity of epoxy thickness on the composite surface. It was obvious that the Raman map of the composite laminate composed of just $\mathrm{COOH}-\mathrm{GNPs}$ appeared to have more blue regions than those of 50:50 and $0: 100 \mathrm{wt} \%$ ratios. This indicated that the sample had the least nanofiller distribution. Moreover, the blue space significantly decreased, indicating the improvement of $\mathrm{COOH}-$ nanofiller distribution, when the epoxy resin contained the nanofiller hybrids at a
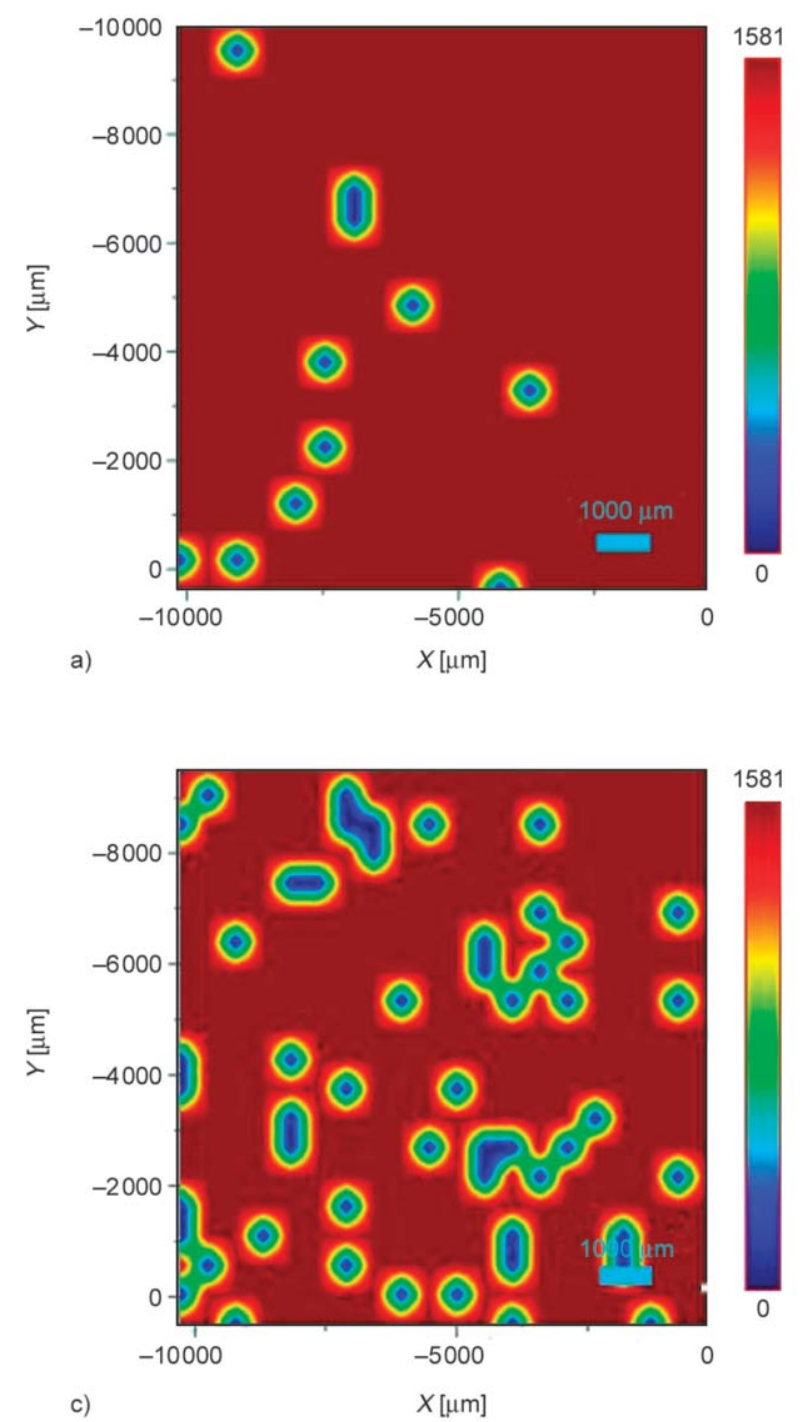

ratio of 50:50 $\mathrm{wt} \%$. These were in good agreement with the AFM mapping results.

Raman mapping images of the $\mathrm{G}$ band at various $\mathrm{COOH}$-nanofiller hybrid concentrations are presented in Figure 4. Simultaneously, the Raman maps of the composite laminates containing nanocarbon hybrids at 4 and $10 \mathrm{phr}$ were chosen to display the distribution state of nanofiller hybrids based on the aforementioned AFM results. The composite laminate containing 50:50 $\mathrm{wt} \% \mathrm{COOH}-\mathrm{GNP}: \mathrm{COOH}-$ MWCNT ratio at $4 \mathrm{phr}$ exhibited a lower amount of blue regions for the $\mathrm{G}$ band compared to that of $1 \mathrm{phr}$ (see Figure 3c). This result showed that the improvement of nanofiller distribution on the sample surface was obtained by adding a high amount of nanofiller hybrids. The blue area dramatically decreased in the mixture at $10 \mathrm{phr}$ since a large amount of nanofiller
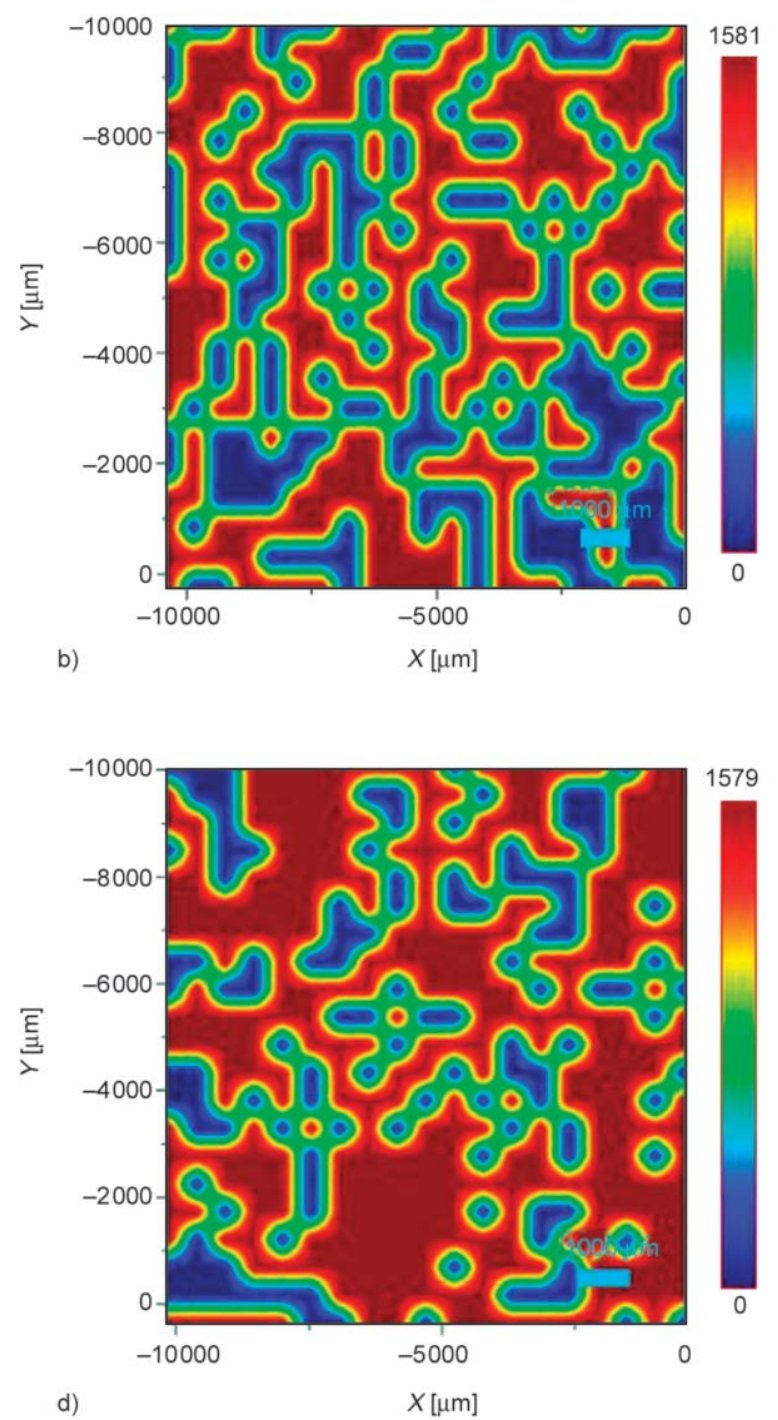

Figure 3. Raman mapping images of $\mathrm{G}$ band regions on the composite surfaces at different COOH-GNP:COOH-MWCNT ratios [wt\%] at 1 phr: (a) 0:0 (unfilled epoxy resin), (b) 100:0 (all COOH-GNP), (c) 50:50, and (d) 0:100 (all COOH-MWCNT). 

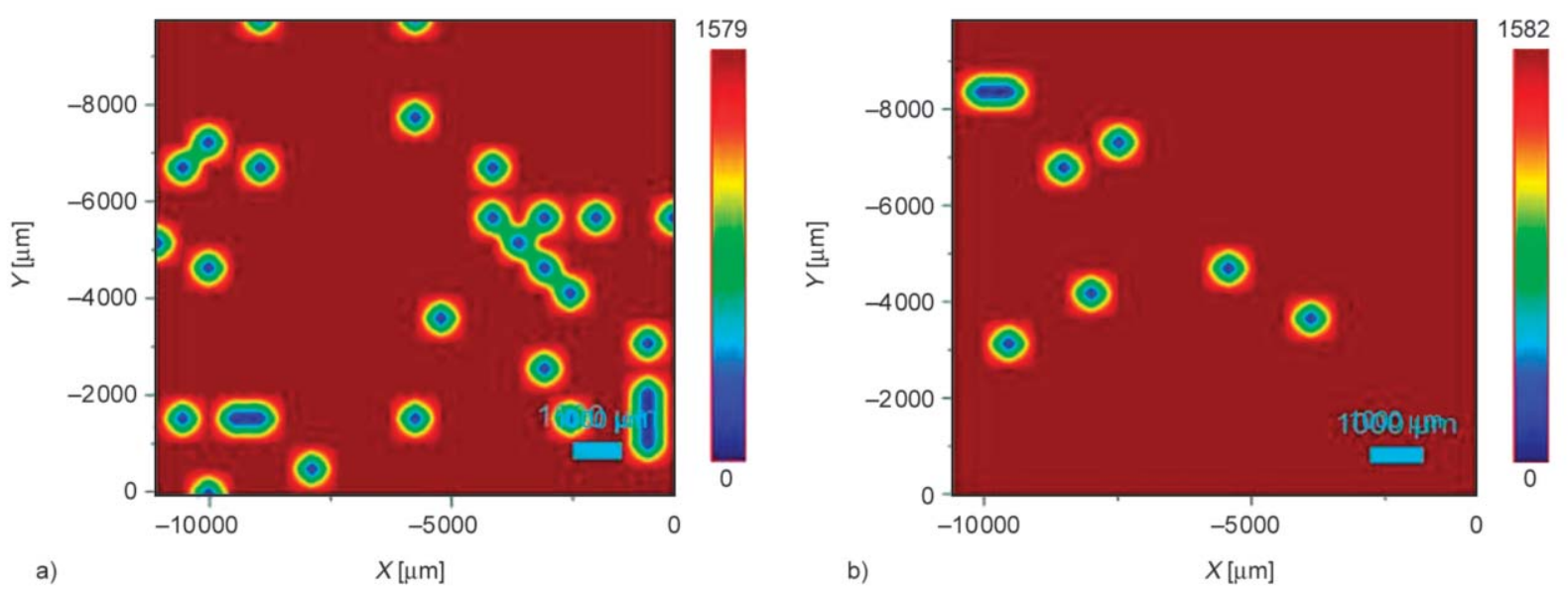

Figure 4. Raman mapping images of $\mathrm{G}$ band areas on composite surfaces at different concentrations of COOH-nanofiller hybrid (50:50 wt\%): (a) 4 and (b) 10 phr.

hybrids in the epoxy resin provided a high opportunity for forming expansive networks on some areas of the composite surface. Nonetheless, the overall distribution of $\mathrm{COOH}$-nanofiller hybrids at $10 \mathrm{phr}$ on the sample surfaces was poor in comparison with $\mathrm{COOH}$-nanofiller hybrids at $4 \mathrm{phr}$. Again the Raman and properties of composite laminates results were in good accordance (see section 3.3. and 3.4.). This might be possibly resulted from high viscosity of the epoxy/nanofiller hybrid suspension at high carbon nanomaterial concentration, causing the difficulty in spreading uniformity of the suspension during hand lay-up and compression molding processes.

\subsection{Electrical conductivity}

The average electrical conductivity of the composite laminates containing various $\mathrm{COOH}-\mathrm{GNP}: \mathrm{COOH}-$ MWCNT ratios and nanofiller hybrid concentrations are reported in Figure 5, respectively. In Figure 5a, the electrical conductivity of the single $\mathrm{COOH}-\mathrm{GNP}$ filled epoxy/CF composite laminate was about 3\%

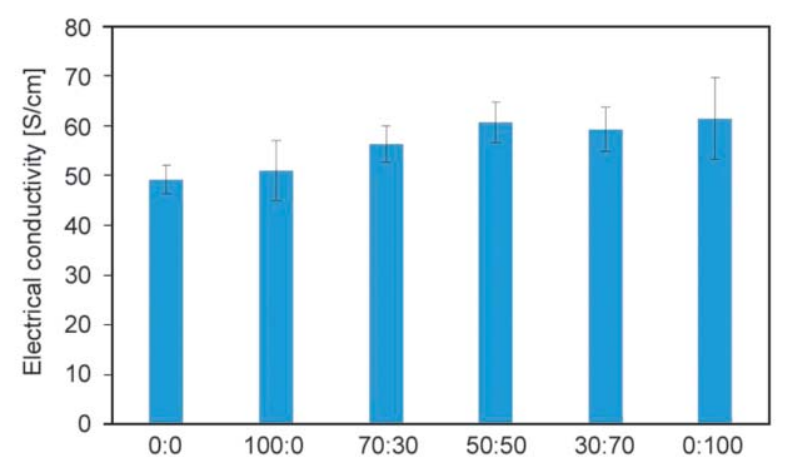

a)

COOH-GNP:COOH-MWCNT ratio [wt\%] higher than that of the unfilled epoxy/CF composite laminate. This was a result of GNP forming electrical bridges to facilitate electron transport throughout the host matrix. It corresponded to the nanofiller dispersion results. The slight intercalation and distribution degrees of modified GNPs in the polymeric matrix resulted in the reduction of the electrical conductivity of nanocomposites [24]. For the single $\mathrm{COOH}-\mathrm{MWCNT}$ added epoxy resin system, the electrical conductivity increased up to $25 \%$ with a large error bar. This might be because of the partial agglomeration of modified MWCNTs. It was revealed that the random distribution of rigid 2D-GNPs was not able to form a conducting network as efficient as the flexible 1D-MWCNTs [32]. The synergetic effect of the combination of 1D-MWCNTs and 2D-GNPs on the electrical conductivity was clearly observed at the ratio of 50:50 $\mathrm{wt} \%$ at $1 \mathrm{phr}$, providing the enhancement of electrical conductivity up to $25 \%$ with a small variation. This was due to improved nanofiller dispersion, facilitating high electrical pathways

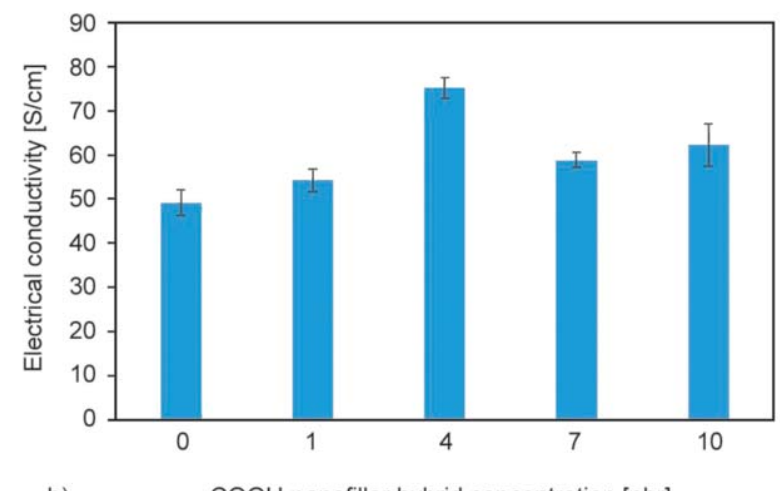

b) $\quad \mathrm{COOH}$-nanofiller hybrid concentration [phr]

Figure 5. The electrical conductivity of composite laminates at different: (a) COOH-GNP:COOH-MWCNT ratios and (b) nanofiller hybrid concentrations. 
within the polymeric matrix [39]. Additionally, at this mixing combination of nanofiller hybrid, the electrical conductivity was $19 \%$ higher than that of a single COOH-GNPs filled epoxy system.

In order to increase the electrical conductivity of composite laminates, higher nanofiller hybrid loadings were added in the epoxy resin at $\mathrm{COOH}$ GNP:COOH-MWCNT ratio of 50:50 wt $\%$. The electrical conductivity continued to go up to $53 \%$, with increasing nanofiller contents from 0 to $4 \mathrm{phr}$. This result could be attributed to the better formation of a hybrid 3D-architecture that promoted the electron transfer throughout the polymer [30, 31, 42], based on the nanofiller hybrid dispersion results. When the amount of nanofiller hybrids was increased to 7 and $10 \mathrm{phr}$, the electrical conductivity began to decline owing to the presence of agglomerated nanofillers. This aggregated structure of nanofiller hybrids resulted in the reduction of a highly conducting network formation [32].

\subsection{Flexural strength}

Using 1D-MWCNT and 2D-GNP combination as nanofiller hybrids rather than the single filler filled system, also provided superior mechanical performance. Figure 6a presents the effect of nanofiller hybrid ratios at $1 \mathrm{phr}$ on the flexural strength of epoxy/ CF composite laminates. The results showed that the flexural strength of CFRP composite laminates increased by adding carbon nanofillers in the system, compared with the unfilled epoxy resin/CF composite laminate. This improvement could be attributed to the enhanced load transfer from the epoxy matrix to the nanofiller reinforcement due to the increased interfacial compatibility between the modified nanofillers and the matrix [29]. However, single $\mathrm{COOH}-$ GNPs seemed to be less efficient than single

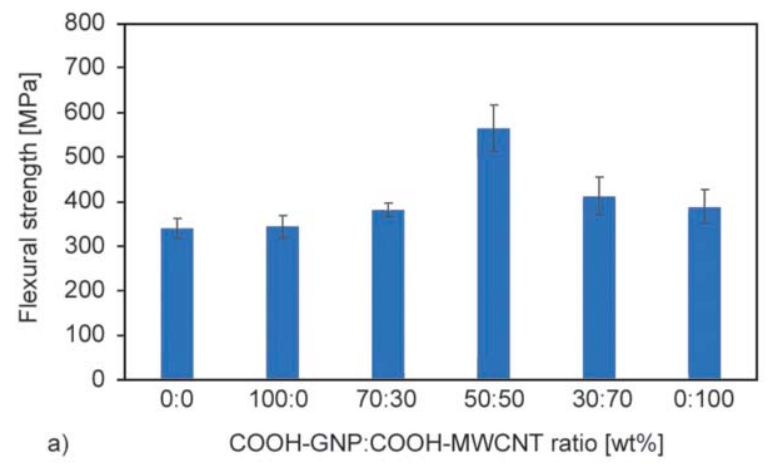

Figure 6. The flexural strength of composite laminates (b) nanofiller hybrid concentrations.
COOH-MWCNTs on enhancing the flexural strength of composite laminates. A negligible difference $(\sim 1 \%)$ with respect to the unfilled epoxy/CF composite laminate was found while that of the single COOH-MWCNTs added epoxy/CF composite laminate was around $14 \%$. The utilization of nanocarbon hybrids promoted a significant enhancement of the flexural strength, particularly for the $\mathrm{COOH}$ GNP:COOH-MWCNT ratio of 50:50 wt $\%$. At this ratio, the flexural strength increased up to 64 and $45 \%$ in comparison with that of the composite laminates containing single $\mathrm{COOH}-\mathrm{GNPs}$ and $\mathrm{COOH}-$ MWCNTs, respectively. Additionally, the flexural strength of the composite laminate at this mixing ratio was also $66 \%$ superior to that of the neat epoxy/CF composite laminate.

Hence, the COOH-GNP:COOH-MWCNT ratio of $50: 50 \mathrm{wt} \%$ with different filled proportions was employed for fabricating nanofiller hybrid filled epoxy/ $\mathrm{CF}$ composite laminates. Figure $6 \mathrm{~b}$ demonstrates the influence of adding nanofiller hybrid at various dosages on the flexural strength of epoxy/CF composite laminates. The flexural strength of composite laminates drastically increased up to $81 \%$ when the content of nanofiller hybrids was raised from 0 to 4 phr due to more connecting networks for load transfer. The synergetic behavior of nanofiller hybrids could be explained by the formation of a 3D-structure that inhibited the re-agglomeration of carbon nanofillers due to their large van der Waals forces and strong $\pi-\pi$ interactions between the nanoplatelets [29]. Furthermore, it was reported that the tube-like structure of MWCNTs in the presence of GNPs caused an entanglement of MWCNTs around GNPs and filled spaces between the interlayer of GNPs. This led to a better interaction between the nanofillers and the matrix $[30,32]$. The mechanism of

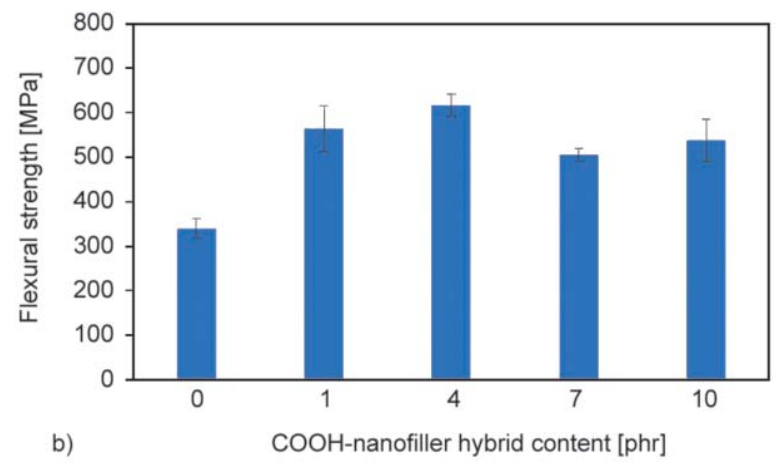

b) (a) COOH-GNP:COOH-MWCNT ratios and 
crack growth suppression in composite laminates mainly involved the inhibition of the major crack development by GNPs and the prevention of minor crack propagation by MWCNTs [28]. Consequently, under the synergetic effect of MWCNTs and GNPs, the interlaminar energy of the epoxy/CF composite laminate was effectively reinforced. However, over nanofiller hybrid contents of 7 and $10 \mathrm{phr}$, the flexural strength distinctly dropped since the filler agglomeration occurred, according to the AFM and Raman mapping results. The filler aggregation acted as micro-size fillers with low surface area or as micro-defects of stress concentration [26].

\section{Conclusions}

The interlaminar interface of epoxy/CF composite laminates was developed using a nanostructural approach of mixing nanofillers of COOH-GNPs and COOH-MWCNTs. The modified nanocarbons were found to improve their dispersion states in epoxy/nanofiller suspension and on the composite laminate surfaces. Furthermore, combinations of 1D-MWCNTs and 2-D GNPs exhibited the synergetic effects on the dispersion capability of nanofillers, electrical conductivity, and mechanical performance, most likely owing to their high potential to form the segregated structure with high connecting networks. Besides, the concentration of carbon nanofiller hybrids also influenced the dispersion of nanofillers and the utimate properties of the composite laminates. In this work, the COOH-GNP:COOH-MWCNT ratio of 50:50 wt $\%$ at $4 \mathrm{phr}$ provided the synergetic effects on the nanofiller dispersion, electrical conductivity, and the performance of multifunctional reinforcement in epoxy/ CF composite laminates. The composition was superior to those containing a single carbon nanomaterial and unfilled epoxy resin. The novel surface potential AFM and Raman mappings demonstrated promising approaches to determine the distribution of nanofillers on the composite laminate surface. The results showed good correlations with the ultimate electrical and mechanical properties of the composite laminates.

\section{Acknowledgements}

The authors would like to express our appreciation to the National Metal and Materials Technology Center (MTEC) for the financial support under MTEC platform program (Project code: P1651961). We also acknowledge Prof. S. Seraphin (NSTDA PAC) for fruitful discussions on manuscript preparation.

\section{References}

[1] Saba N., Jawaid M., Alothman O. Y., Paridah M., Hassan A.: Recent advances in epoxy resin, natural fiber-reinforced epoxy composites and their applications. Journal of Reinforced Plastics and Composites, 35, 447-470 (2016). https://doi.org/10.1177/0731684415618459

[2] Chung D. D. L.: Polymer-matrix composites. in 'Carbon fiber composites' (ed.: Chung D. D. L.) ButterworthHeinemann, Newton, 85-123 (2012). https://doi.org/10.1016/B978-0-08-050073-7.50010-5

[3] Han S., Lin J. T., Yamada Y., Chung D. D. L.: Enhancing the thermal conductivity and compressive modulus of carbon fiber polymer-matrix composites in the through-thickness direction by nanostructuring the interlaminar interface with carbon black. Carbon, 46, 1060-1071 (2008).

https://doi.org/10.1016/j.carbon.2008.03.023

[4] Chiou Y-C., Chou H-Y., Shen M-Y.: Effects of adding graphene nanoplatelets and nanocarbon aerogels to epoxy resins and their carbon fiber composites. Materials and Design, 178, 107869/1-107869/11 (2019). https://doi.org/10.1016/J.MATDES.2019.107869

[5] Jiang J., Xu C., Su Y., Guo Q., Liu F., Deng C., Yao X., Zhou L.: Influence of carbon nanotube coatings on carbon fiber by ultrasonically assisted electrophoretic deposition on its composite interfacial property. Polymers, 8, 302/1-302/11 (2016). https://doi.org/10.3390/polym8080302

[6] El Moumen A., Tarfaoui M., Lafdi K., Benyahia H.: Dynamic properties of carbon nanotubes reinforced carbon fibers/epoxy textile composites under low velocity impact. Composites Part B: Engineering, 125, 1-8 (2017). https://doi.org/10.1016/j.compositesb.2017.05.065

[7] Thostenson E. T., Ren Z., Chou T-W.: Advances in the science and technology of carbon nanotubes and their composites: A review. Composites Science and Technology, 61, 1899-1912 (2001). https://doi.org/10.1016/S0266-3538(01)00094-X

[8] Qin W., Vautard F., Drzal L. T., Yu J.: Mechanical and electrical properties of carbon fiber composites with incorporation of graphene nanoplatelets at the fiber-matrix interphase. Composites Part B: Engineering, 69, 335-341 (2015).

https://doi.org/10.1016/j.compositesb.2014.10.014

[9] Kim S., Drzal L. T.: Comparison of exfoliated graphite nanoplatelets $(\mathrm{xGnP})$ and CNTs for reinforcement of EVA nanocomposites fabricated by solution compounding method and three screw rotating systems. Journal of Adhesion Science and Technology, 23, 1623-1638 (2009).

https://doi.org/10.1163/156856109X440984

[10] Zhao X., Zhang Q., Chen D., Lu P.: Enhanced mechanical properties of graphene-based poly(vinyl alcohol) composites. Macromolecules, 43, 2357-2363 (2010). https://doi.org/10.1021/ma902862u 
[11] Aalaie J., Rahmatpour A., Maghami S.: Preparation and characterization of linear low density polyethylene/carbon nanotube nanocomposites. Journal of Macromolecular Science Part B: Physics, 46, 877-889 (2007). https://doi.org/10.1080/00222340701389100

[12] Zhan Y., Wu J., Xia H., Yan N., Fei G., Yuan G.: Dispersion and exfoliation of graphene in rubber by an ultrasonically-assisted latex mixing and in situ reduction process. Macromolecular Materials and Engineering, 296, 590-602 (2011).

https://doi.org/10.1002/mame.201000358

[13] Ahmadi-Moghadam B., Taheri F.: Effect of processing parameters on the structure and multi-functional performance of epoxy/GNP-nanocomposites. Journal of Materials Science, 49, 6180-6190 (2014).

https://doi.org/10.1007/s10853-014-8332-y

[14] Loos M. R., Yang J., Feke D. L., Manas-Zloczower I.: Effect of block-copolymer dispersants on properties of carbon nanotube/epoxy systems. Composites Science and Technology, 72, 482-488 (2012). https://doi.org/10.1016/j.compscitech.2011.11.034

[15] Ma P-C., Siddiqui N. A., Marom G., Kim J-K.: Dispersion and functionalization of carbon nanotubes for polymer-based nanocomposites: A review. Composites Part A: Applied Science and Manufacturing, 41, 1345-1367 (2010). https://doi.org/10.1016/j.compositesa.2010.07.003

[16] Wang Z., Colorad H. A., Guo Z-H., Kim H., Park C-L., Hahn H. T., Lee S-G., Lee K-H., Shang Y-Q.: Effective functionalization of carbon nanotubes for bisphenol $\mathrm{F}$ epoxy matrix composites. Materials Research, 15, 510 516 (2012).

https://doi.org/10.1590/S1516-14392012005000092

[17] Yadav S. K., Cho J. W.: Functionalized graphene nanoplatelets for enhanced mechanical and thermal properties of polyurethane nanocomposites. Applied Surface Science, 266, 360-367 (2013).

https://doi.org/10.1016/j.apsusc.2012.12.028

[18] Yuan B., Bao C., Song L., Hong N., Liew K. M., Hu Y.: Preparation of functionalized graphene oxide/polypropylene nanocomposite with significantly improved thermal stability and studies on the crystallization behavior and mechanical properties. Chemical Engineering Journal, 237, 411-420 (2014). https://doi.org/10.1016/j.cej.2013.10.030

[19] Kim Y. J., Shin T. S., Choi H. D., Kwon J. H., Chung Y-C., Yoon H. G.: Electrical conductivity of chemically modified multiwalled carbon nanotube/epoxy composites. Carbon, 43, 23-30 (2005).

https://doi.org/10.1016/j.carbon.2004.08.015

[20] Gojny F. H., Wichmann M. H. G., Fiedler B., Kinloch I. A., Bauhofer W., Windle A. H., Schulte K.: Evaluation and identification of electrical and thermal conduction mechanisms in carbon nanotube/epoxy composites. Polymer, 47, 2036-2045 (2006).

https://doi.org/10.1016/j.polymer.2006.01.029
[21] Kim H., Abdala A. A., Macosko C. W.: Graphene/polymer nanocomposites. Macromolecules, 43, 6515-6530 (2010).

https://doi.org/10.1021/ma100572e

[22] Alam A., Wan C., McNally T.: Surface amination of carbon nanoparticles for modification of epoxy resins: Plasma-treatment $v s$. wet-chemistry approach. European Polymer Journal, 87, 422-448 (2017). https://doi.org/10.1016/j.eurpolymj.2016.10.004

[23] Roy S., Das T., Zhang L., Li Y., Ming Y., Ting S., Hu X., Yue C. Y.: Triggering compatibility and dispersion by selective plasma functionalized carbon nanotubes to fabricate tough and enhanced Nylon 12 composites. Polymer, 58, 153-161 (2015).

https://doi.org/10.1016/j.polymer.2014.12.032

[24] Poosala A., Hrimchum K., Aussawasathien D., Pentrakoon D.: The effect of oxygen-plasma treated graphene nanoplatelets upon the properties of multiwalled carbon nanotube and polycarbonate hybrid nanocomposites used for electrostatic dissipative applications. Journal of Nanomaterials, 2015, 470297/1470297/9 (2015).

https://doi.org/10.1155/2015/470297

[25] Prasad K. E., Das B., Maitra U., Ramamurty U., Rao C. N. R.: Extraordinary synergy in the mechanical properties of polymer matrix composites reinforced with 2 nanocarbons. Proceedings of the National Academy of Sciences of the United States of America, 106, 1318613189 (2009). https://doi.org/10.1073/pnas.0905844106

[26] Yang S-Y., Lin W-N., Huang Y-L., Tien H-W., Wang J-Y., Ma C-C. M., Li S-M., Wang Y-S.: Synergetic effects of graphene platelets and carbon nanotubes on the mechanical and thermal properties of epoxy composites. Carbon, 49, 793-803 (2011).

https://doi.org/10.1016/j.carbon.2010.10.014

[27] Im H., Kim J.: Thermal conductivity of a graphene oxide-carbon nanotube hybrid/epoxy composite. Carbon, 50, 5429-5440 (2012).

https://doi.org/10.1016/j.carbon.2012.07.029

[28] Wang P-N., Hsieh T-H., Chiang C-L., Shen M-Y.: Synergetic effects of mechanical properties on graphene nanoplatelet and multiwalled carbon nanotube hybrids reinforced epoxy/carbon fiber composites. Journal of Nanomaterials, 2015, 838032/1-838032/9 (2015). https://doi.org/10.1155/2015/838032

[29] Yue L., Pircheraghi G., Monemian S. A., ManasZloczower I.: Epoxy composites with carbon nanotubes and graphene nanoplatelets - Dispersion and synergy effects. Carbon, 78, 268-278 (2014). https://doi.org/10.1016/j.carbon.2014.07.003

[30] Kumar S., Sun L. L., Caceres S., Li B., Wood W., Perugini A., Maguire R. G., Zhong W. H.: Dynamic synergy of graphitic nanoplatelets and multi-walled carbon nanotubes in polyetherimide nanocomposites. Nanotechnology, 21, 105702/1-105702/10 (2010). https://doi.org/10.1088/0957-4484/21/10/105702 
[31] Li W., Dichiara A., Bai J.: Carbon nanotube-graphene nanoplatelet hybrids as high-performance multifunctional reinforcements in epoxy composites. Composites Science and Technology, 74, 221-227 (2013). https://doi.org/10.1016/j.compscitech.2012.11.015

[32] Safdari M., Al-Haik M. S.: Synergistic electrical and thermal transport properties of hybrid polymeric nanocomposites based on carbon nanotubes and graphite nanoplatelets. Carbon, 64, 111-121 (2013). https://doi.org/10.1016/j.carbon.2013.07.042

[33] Sun S., Zhang Z., Wu P.: Exploring graphene nanocolloids as potential substrates for the enhancement of Raman scattering. ACS Applied Materials and Interfaces, 5, 5085-5090 (2013). https://doi.org/10.1021/am400938z

[34] O’Connell M. J., Bachilo S. M., Huffman C. B., Moore V. C., Strano M. S., Haroz E. H., Rialon K. L., Boul P. J., Noon W. H., Kittrell C., Ma J., Hauge R. H., Weisman R. B., Smalley R. E.: Band gap fluorescence from individual single-walled carbon nanotubes. Science, 297, 593-596 (2002). https://doi.org/10.1126/science. 1072631

[35] Yu J., Grossiord N., Koning C. E., Loos J.: Controlling the dispersion of multi-wall carbon nanotubes in aqueous surfactant solution. Carbon, 45, 618-623 (2007). https://doi.org/10.1016/j.carbon.2006.10.010

[36] Li D., Müller M. B., Gilje S., Kaner R. B., Wallace G. G.: Processable aqueous dispersions of graphene nanosheets. Nature Nanotechnology, 3, 101-105 (2008). https://doi.org/10.1038/nnano.2007.451
[37] Fan Z., Advani S. G.: Rheology of multiwall carbon nanotube suspensions. Journal of Rheology, 51, 585-604 (2007). https://doi.org/10.1122/1.2736424

[38] Ke K., Wang Y., Luo Y., Yang W., Xie B-H., Yang M-B.: Evolution of agglomerate structure of carbon nanotubes in multi-walled carbon nanotubes/polymer composite melt: A rheo-electrical study. Composites Part B: Engineering, 43, 3281-3287 (2012). https://doi.org/10.1016/j.compositesb.2012.02.011

[39] Allaoui A., Bai S., Cheng H. M., Bai J. B.: Mechanical and electrical properties of a MWNT/epoxy composite. Composites Science and Technology, 62, 1993-1998 (2002). https://doi.org/10.1016/S0266-3538(02)00129-X

[40] Ferrari A. C., Robertson J.: Interpretation of Raman spectra of disordered and amorphous carbon. Physical Review B, 61, 14095-14107 (2000). https://doi.org/10.1103/PhysRevB.61.14095

[41] Saito R., Hofmann M., Dresselhaus G., Jorio A., Dresselhaus M. S.: Raman spectroscopy of graphene and carbon nanotubes. Advances in Physics, 60, 413-450 (2011). https://doi.org/10.1080/00018732.2011.582251

[42] Li J., Wong P-S., Kim J-K.: Hybrid nanocomposites containing carbon nanotubes and graphite nanoplatelets. Materials Science and Engineering: A, 483-484, 660663 (2008).

https://doi.org/10.1016/j.msea.2006.08.145 